\title{
Performance Improvement of Suspension Characteristics by Implementation of Active Suspension System in Two Wheelers
}

\author{
A. Backiyaraj ${ }^{1,}$, M. Parthasarathy ${ }^{1}$, N. Murugu Nachippan ${ }^{1}$ and T. Kumaran² \\ ${ }^{1}$ Department of Automobile Engineering, Vel Tech Rangarajan Dr. Sagunthala R\&D Institute of Science and Technology, 600062, Tamil Nadu, \\ India \\ 2Department of Aeronautical Engineering, Vel Tech Rangarajan Dr. Sagunthala R\&D Institute of Science and Technology, 600062 Tamil Nadu, \\ India
}

\begin{abstract}
New and better two-wheel models have increased demand today, with increased protection, comfort and performance. The human body gets exhausted, which contributes to back pain and neck pain because of the excessive use of bikes, wrong riding positions, poor weather and suspension system issues. The systems engineer would focus on the design of the vehicle suspension mechanism to minimise human discomfort. This research aims to study the feasibility of implementing a suspension system with active suspension for a two-wheeler by way of numerical modelling, simulation and analysis. First of all, the active suspension system for a 2 DOF system is modelled and analysed. The analysis done is frequency response analysis and time-domain analysis. The time-domain analysis is done using two road inputs; one is a bump input, which is designed according to the standards, and the other is a random road input. Then the two-wheelers were modelled as a 4 DOF model. The controller is modelled using optimal control theory. A linear quadratic regulator (LQR) controller is used because the system is assumed to have linear characteristics and the cost function of the system is quadratic. It is observed that suspension characteristics are improved by using the active suspension system in two-wheelers.
\end{abstract}

ARTICLE HISTORY

Received: $26^{\text {th }}$ Jan 2021

Revised: 21st Sept 2021

Accepted: $14^{\text {th }}$ Oct 2021

\section{KEYWORDS}

Active suspension system; LQR control design;

Random road input;

Bump profile;

Road profile

\section{INTRODUCTION}

Researches for the development of suspension systems that can give very good ride comfort along with crisp handling have been of great theoretical and practical importance for the past four decades. Objectives of the suspension systems are hard to implement due to the conflicting nature of the suspension system. Any vehicle without suspension moving over the irregular road will have difficulties getting road grip and cause discomfort to the rider. To absorb road bumps, the appropriate suspension must be provided to the vehicle. A vehicle with a suspension system may be called a wheelconnected lumping system with elastic structures (suspension springs). The lumped body consists of chassis, engine, transmission, passengers. The mass supported by the suspension system is referred to as sprung mass. The masses that are not supported by the suspension mechanism are un-sprung masses (brakes, wheels, tyres). The suspension mass is measured as half sprung and half un-sprung.

The research proposed frequency-based parametric bandwidth sensitivity studies of both the suspension dynamics of motor vehicles and the power transmission capability in accordance with the sensitivity models. This gives insights into the suspension parameter that could significantly increase the magnitude of the harvestable capacity, which contributes positively to the conceptualisation of an optimal configuration of a broad-band energy harvesting damper that leads to better harvesting efficiencies under various road conditions [1]. This paper shows versions of fifth, half and full suspension cars, combined in the same base vehicle with adaptive shock absorbers. The time domain and frequency dominance analysis enable the three suspension system models to be compared considerably concerning the effects of vehicle speed, vehicle centre of gravity location, road classifications and speed cycles [2]. The magnet springs with a negative rigidity can be used to minimise turbulence on car drivers by a semi-active seat suspension. A comprehensive simulation and experimental validation analysis based on static and vibration responses show that NSMS provides the seat suspension with advantageous low ruggedness and reduces vibration frequency during vertical arousal without affecting the load power [3].

The influence of the MR-damper reaction time on a full-car semi-active suspension system vibration control has been subject to uncertainty with the parameters. A complete vehicle having seven DOF in the suspension system, taking into account the actuator time constant after a short analysis of the reaction time properties of the MR rapid-response damper. Three separate motions are consequently formulated using a robust sliding mode controller to achieve optimal vibration regulation of the suspension mechanism [4]. One configuration with best plane enforcement is then evaluated for mechanism variable output sensitivity and parasite error, thereby providing details about the design area. Rotational rigidity is determined based on numerical simulation in the in-plane rotational axis and tension [5-8]. In view of the linearity and nonlinearity method of the mechanism, a passive control system was tested. A system fourth car model has 
been established for comparative analysis. The model incorporates nonlinear in the rigidity and damping of the vehicle suspension. A Finite Element (FE) model was initially developed, taking into account the major CM sub-assemblies [9, 10]. A stress life curve is used in the same study to predict the failure mode of the rolls in the vehicle body. In order to achieve the failure mode of a part, the stress curve, the background of residual stress cycles and the mechanical property of the part are needed [11]. A vehicle with a suspension system can be modelled analogous to an inverted spring-mass system, with road inputs as base excitations. The number of degrees of freedom of the system depends on the type of the vehicle and the number of motions we are interested to study. For a two-wheeler, modelling of in-plane dynamics requires a 4-DOF model. Effects and parameters on priorities and optimal parameter combinations are defined via the Taguchi matrix calculations. The optimised approach is evaluated under the excitation of the road surface profiles [12-19].

\section{METHODOLOGY}

The present work is in the area of active suspension for two-wheelers. Two-wheelers are the mode of transport for a common person. When compared to four-wheelers, they are very light, and their suspension systems are not that much sophisticated. Due to the sitting posture, there is a greater risk of back and neck injury due to prolonged usage of twowheelers. This project aims at numerical modelling and analysis of an active suspension system in two-wheelers. Unlike cars, two-wheelers are very light in weight, and hence the control forces required for active suspension controllers will be very small. For each iteration, the state space analysis and the transfer function is solved, and the frequency response has been found out by bode plot. Based on the DOF, the iterations were carried out.

\section{NUMERICAL MODELLING}

\section{Linear Quadratic Regulator State Feedback Design}

A linear time-invariant system can be expressed in state variable form as

$$
\dot{x}=A x+B u
$$

With $x(t) \in R^{n}, u(t) \in R^{m}$, with zero initial condition. It is assumed here that all the states are measurable and statevariable feedback (SVFB) control can be given as

$$
u=-K x+v
$$

It provides the necessary closed-loop characteristics. This control creates a closed-loop system.

$$
\dot{x}=(A-B K) x+B v=A_{c} x+B v
$$

where $v(t)$ is the disturbance input, and $A_{c}$ is the closed-loop plant matrix. In the state-variable feedback concept, the output matrices $C$ and $D$ are not employed.

The performance index is used to create an optimum state-variable feedback system.

$$
J=\frac{1}{2} \int_{0}^{\infty}\left(x^{T} Q x+2 x^{T} N u+u^{T} R u\right) d t
$$

where $Q$ is state weighing matrix $(n \times n), N$ is cross coupled cost matrix $(n \times m)$, and $R$ is control input weighing matrix $(m \times m)$ matrix. Substituting the state-variable feedback design control into this yields

$$
J=\frac{1}{2} \int_{0}^{\infty} x^{T}\left(Q+K^{T} R K\right) x d t
$$

where $v(t)$ can be assumed to be zero since it is the plant disturbance matrix, and the control gain will be independent of the plant disturbance.

\section{State Space Analysis}

Choosing the state variables as $X 1=Z_{s}-Z_{u s}$ (Suspension deflection), $X 2=Z_{s}$ (Absolute velocity of sprung mass), $X 3=Z_{u s}-Z_{r}$ (Tyre deflection), $X 4=Z_{u s}^{\cdot}$ (Absolute velocity of unsprung mass), the system's state space representation is as follows:

$$
\dot{X}=A X+B F_{a}+L \dot{Z}_{r}(\text { State equation })
$$

where, 


$$
A=\left[\begin{array}{cccc}
0 & 1 & 0 & -1 \\
-\frac{K_{s}}{m_{S}} & -\frac{B_{s}}{m_{s}} & 0 & \frac{B_{s}}{m_{s}} \\
0 & 0 & 0 & 1 \\
\frac{K_{s}}{m_{u s}} & \frac{B_{s}}{m_{u s}} & -\frac{K_{t}}{m_{u s}} & -\frac{B_{s}}{m_{u s}}
\end{array}\right] B=\left[\begin{array}{c}
0 \\
\frac{1}{m_{s}} \\
0 \\
-\frac{1}{m_{u s}}
\end{array}\right] L=\left[\begin{array}{c}
0 \\
0 \\
-1 \\
0
\end{array}\right]
$$

Normal tyre load is the most important factor which affects acceleration, braking and cornering power. This is because all these reaction forces are due to friction between tyre and rod, and frictional forces are directly related to normal tyre loads. The typical tyre load varies linearly because the tyre behaves like a spring when subjected to vertical loads. (assuming linear spring characteristics) linearly with tyre deflection. Tyre deflection can be defined as the difference between un-sprung mass and road input, $Z_{u s}-Z_{r}$. Static deflection of the tyre can be calculated using the formula,

$$
\delta_{t}=\left(\left(m_{s}+m_{u s}\right) \times g\right) / K_{t}
$$

Normal tyre load is calculated by the formula,

$$
N_{l}=\left(\delta_{t}-\left(Z_{u s}-Z_{r}\right)\right) \times K_{t}
$$

In the above expression, $Z_{u s}-Z_{r}$ is the tyre deflection. It is clear that excessive tyre deflection reduces the normal tyre load, which directly affects acceleration, braking and cornering abilities.

$F_{a}$ is the actuator force $\left(F_{a}=-K \times X\right)$ and $\dot{Z}_{r}$ is the (ground vertical velocity) disturbance input. Since $F_{a}=-K \times X$, substituting and modifying the state equation, it becomes,

$$
\dot{X}=A_{c} X+L_{-} \dot{Z}_{r}
$$

where $A_{c}$ is the closed loop plant matrix. Closed loop gain can be obtained by solving the algebraic Ricatti equation as given previously. For a 2 DOF model, The cost function may be expressed as follows:

$$
J=\int_{0}^{\infty}\left(\ddot{Z}_{s}^{2}+\rho_{1}\left(Z_{s}-Z_{u}\right)^{2}+\rho_{2} \dot{Z}_{s}^{2}+\rho_{3}\left(Z_{u}-Z_{r}\right)^{2}+\rho_{4} \dot{Z}_{u}^{2}\right) d t
$$

For a general system, The cost function may be expressed as follows:

$$
J=\frac{1}{2} \int_{0}^{\infty}\left(x^{T} Q x+2 x^{T} N u+u^{T} R u\right) d t
$$

Substituting the expression for $\ddot{Z}_{s}$, and expanding, $J$ can be obtained as

$$
\begin{aligned}
J=\int_{0}^{\infty} \rho_{1} X 1^{2} & +\rho_{2} X 2^{2}+\rho_{3} X 3^{2}+\rho_{4} X 4^{2}+\frac{F_{a}^{2}}{m_{s}^{2}}+\frac{B_{S}^{2} X 2^{2}}{m_{s}^{2}}+\frac{B_{S}^{2} X 4^{2}}{m_{s}^{2}}+\frac{K_{s}^{2} X 1^{2}}{m_{s}^{2}}-\frac{2 F_{a} B_{S} X 2}{m_{S}^{2}}+\frac{2 F_{a} B_{S} X 4}{m_{s}^{2}} \\
& -\frac{2 F_{a} K_{s} X 1}{m_{S}^{2}}-\frac{2 B_{s}^{2} X 2 X 4}{m_{s}^{2}}+\frac{2 B_{S} K_{S} X 1 X 2}{m_{s}^{2}}-\frac{2 B_{s} K_{S} X 1 X 4}{m_{s}^{2}}
\end{aligned}
$$

To obtain the matrices $\mathrm{Q}, \mathrm{N}, \mathrm{R}$, the coefficients are to be equated to those in generalised equation. Thus $Q, N, R$ is obtained as:

$$
Q=\left[\begin{array}{cccc}
\frac{K_{s}^{2}}{m_{s}^{2}}+\rho_{1} & \frac{B_{s} K_{s}}{m_{s}^{2}} & 0 & -\frac{B_{s} K_{s}}{m_{s}^{2}} \\
\frac{B_{s} K_{s}}{m_{s}^{2}} & \frac{B_{s}^{2}}{m_{s}^{2}}+\rho_{2} & 0 & -\frac{B_{s}^{2}}{m_{s}^{2}} \\
0 & 0 & \rho_{3} & 0 \\
-\frac{B_{s} K_{s}}{m_{s}^{2}} & -\frac{B_{s}^{2}}{m_{s}^{2}} & 0 & \frac{B_{s}^{2}}{m_{s}^{2}}+\rho_{4}
\end{array}\right], \quad N=\left\{\begin{array}{c}
-\frac{K_{s}}{m_{s}^{2}} \\
-\frac{B_{s}}{m_{s}^{2}} \\
0 \\
\frac{B_{s}}{m_{s}^{2}}
\end{array}\right\}, \quad R=\frac{1}{m_{s}^{2}}
$$

\section{Transfer Function Analysis}

Transfer functions of interest are:

Sprung mass acceleration transfer function,

$$
F_{A}(s)=\frac{\ddot{z}_{S}(s)}{\dot{z}_{r}(s)}
$$


Suspension deflection transfer function,

$$
F_{S D}(s)=\frac{z_{S}(s)-z_{u}(s)}{\dot{z}_{r}(s)}
$$

Tyre deflection transfer function

$$
F_{T D}(s)=\frac{z_{u}(s)-z_{r}(s)}{\dot{z}_{r}(s)}
$$

From the governing equations,

$$
\begin{gathered}
m_{s} \ddot{Z}_{s}+B_{s}\left(\dot{Z_{s}}-Z_{u s}^{\cdot}\right)+K_{s}\left(Z_{s}-Z_{u s}\right)=-K 1 \times\left(Z_{s}-Z_{u s}\right)-K 2 \times \dot{Z}_{s}-K 3 \times\left(Z_{u s}-Z_{r}\right)-K 4 \times Z_{u s}^{\cdot} \\
m_{u s}+B_{s}\left(Z_{u s}^{\cdot}-\dot{Z}_{s}\right)+K_{s}\left(Z_{u s}-Z_{s}\right)+K_{t}\left(Z_{u s}-Z_{r}\right)=K 1 \times\left(Z_{s}-Z_{u s}\right)+K 2 \times \dot{Z}_{s}+K 3 \times\left(Z_{u s}-Z_{r}\right)+K 4 \times Z_{u s}
\end{gathered}
$$

To get sprung mass acceleration transfer function, apply the Laplace transform to the governing equations i.e. substitute $Z_{S}=\frac{\ddot{Z}_{s}}{s^{2}}, Z_{u s}=\frac{Z_{u s}}{s^{2}}, \dot{Z}_{s}=\frac{\ddot{Z}_{S}}{s}, Z_{u s}^{\cdot}=\frac{Z_{u s}}{s}$ and $Z_{r}=\frac{\ddot{z}_{r}}{s}$. After simplifying and writing in matrix form, it becomes

$$
\left[\begin{array}{cc}
s^{2} m_{S}+s B_{s}+K_{s}+K 1+s K_{2} & -\left(K_{s}+K 1+s B_{s}-s K 4-K 3\right) \\
-K 1-K_{s}-s B_{S}-s K_{2} & s^{2} m_{u s}+K_{S}+K_{1}+K_{t}-K_{3}+s B_{s}-s K_{4}
\end{array}\right]\left\{\begin{array}{c}
\ddot{Z}_{s} \\
Z_{u s}
\end{array}\right\}=\left\{\begin{array}{c}
s K 3 \\
s K_{t}-s K 3
\end{array}\right\} \dot{Z}_{r}
$$

To get the required sprung mass acceleration transfer function, Cramer's rule is applied. Thus, the obtained transfer function is

$$
\begin{gathered}
F_{A}=\frac{s\left\{m_{u s} K 3 s^{2}+\left(B_{s}-K 4\right) K_{t} s+\left(K_{s}+K 1\right) K_{t}\right\}}{d(s)} \\
d(s)=m_{s} m_{u s} s^{4}+\left\{\left(B_{s}+K 2\right) m_{u s}+\left(B_{s}-K 4\right) m_{s}\right\} s^{3}+\left\{\left(K_{s}+K 1\right) m_{u s}+\left(K_{t}+K_{s}+K 1-K 3\right) m_{s}\right\} s^{2} \\
+\left\{\left(B_{s}+K 2\right) K_{t}\right\} s+\left\{\left(K_{S}+K 1\right) K_{t}\right\}
\end{gathered}
$$

\section{Suspension deflection transfer function}

To get suspension deflection transfer function, apply Laplace transform to the governing equations and substitute $\ddot{Z}_{S}=$ $s^{2} Z_{s}, \dot{Z}_{s}=s Z_{s}, \ddot{Z_{u s}}=s^{2} Z_{u s}, \dot{Z_{u s}}=s Z_{u s}$ and $Z_{r}=\frac{\dot{Z}_{r}}{s}$. After simplifying and writing in matrix form, it becomes

$$
\left[\begin{array}{cc}
s^{2} m_{s}+K_{s}+s B_{S}+K 1+s K 2 & -K_{s}-s B_{S}-K 1+K 3+s K 4 \\
-K_{s}-s B_{S}-K 1-s K 2 & s^{2} m_{u s}+K_{s}+s B_{S}+K_{t}+K 1-K 3-s K 4
\end{array}\right]\left\{\begin{array}{l}
Z_{s} \\
Z_{u s}
\end{array}\right\}=\left\{\begin{array}{c}
\frac{K 3}{s} \\
\frac{K_{t}-K 3}{s}
\end{array}\right\} \dot{Z}_{r}
$$

From this matrix form, $\frac{Z_{s}}{Z_{r}}$ and $\frac{Z_{u s}}{Z_{r}}$ can be found out separately and $\frac{Z_{S}-Z_{u s}}{Z_{r}}$ gives the necessary suspension deflection transfer function.

$$
F_{S D}=\frac{s\left\{K 3 m_{u s}-\left(K_{t}-K 3\right) m_{s}\right\}-(K 2+K 4) K_{t}}{d(s)}
$$

To derive tyre deflection transfer function, we know that $\frac{Z_{r}}{\dot{Z}_{r}}=\frac{1}{s}$. Hence, the required transfer function $\frac{Z_{u s}-Z_{r}}{\dot{Z}_{r}}=\frac{Z_{u s}}{\dot{Z}_{r}}-$ $\frac{Z_{r}}{Z_{\dot{r}}}=\frac{Z_{u s}}{Z_{\dot{r}}}-\frac{1}{S}$

$$
F_{T D}=\frac{m_{u s} m_{S} s^{3}+\left\{\left(B_{S}-K 4\right) m_{s}+\left(B_{S}+K 2\right) m_{u s}\right\} s^{2}+\left(K_{S}+K 1\right)\left(m_{u s}+m_{S}\right) s}{d(s)}
$$

Frequency response can be found out by finding a bode plot of the above transfer functions.

\section{RESULTS AND DISCUSSION}

\section{DOF Planar Model}

Modelling, simulation and analysis have been carried out in MATLAB. The DOF planar model is considered based on the road input modelling and random road profile. Apart from stem and impulse input, the response of the system is analysed for bump and random road input. Speed breakers have certain regulations about the profile, width and height. 
Its longitudinal profile should be part of a circle, the width of the bump varies between 30 and $90 \mathrm{~cm}$ and the height varies between 3 and $10 \mathrm{~cm}$. Figure 1 shows the bump profile.

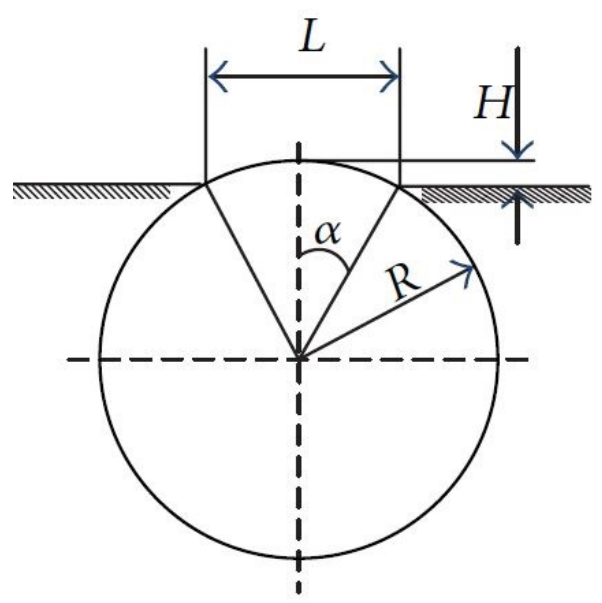

Figure 1. Bump profile.

The bump can be modelled with two input specifications: length of the bump $(L)$ and height of the bump $(H)$. The artificial road profile from ISO classification can be generated by the formula

$$
\mathrm{h}(\mathrm{x})=\sum_{i=0}^{N} \sqrt{\delta n} \cdot 2^{k} \cdot 10^{-3} \cdot\left(\frac{n_{o}}{i \cdot \delta n}\right) \cdot \cos \left(2 \pi \cdot i \cdot \delta n \cdot x+\psi_{i}\right)
$$

where $\delta n$ is the discretisation step, $K$ is the road roughness classification number, value varies from 3 to 9 , and $n_{o}$ is the spatial frequency and $\psi$ is the angular spatial frequency. The above equation gives the random road profile in Cartesian coordinates. By assuming road parameters, and the velocity of the vehicle, the random road can be modelled in the time domain.

\section{Frequency Domain Analysis}

Frequency response analysis is done to see the response of the system in a frequency range. It helps to tune the system to a particular frequency. Figure 2(a) shows the frequency response for the sprung mass acceleration. Comparisons are made for the system with three cases. Case 1 is for heavily weighted ride comfort. The weighting factors selected such that more penalty is imposed on the acceleration term $\left(\rho_{1}=0.4, \rho_{2}=0.16, \rho_{3}=0.4, \rho_{4}=0.16\right)$ in the quadratic cost function. The gain reduces to about $5 \mathrm{~dB}$. The gain does not reduce at the second natural frequency. This may be due to the presence of the gain term g3. G3 can be set to zero without affecting the low frequency of the system. Case 2 is the frequency response for heavily weighted suspension and tyre deflections. The acceleration transfer function deteriorates throughout the frequency range. It has the weighting terms $\left(\rho_{1}=400, \rho_{2}=16, \rho_{3}=400, \rho_{4}=16\right)$. Case 3 shows the transfer function for heavily weighted suspension and tyre. The four weighting terms are $\left(\rho_{1}=10000, \rho_{2}=100, \rho_{3}=10000, \rho_{4}=100\right)$. Sprung mass acceleration has the frequency response somewhat identical as case 2 and has $20 \mathrm{~dB}$ gain at $1 \mathrm{rad} / \mathrm{s}$, which is the typical value for the sprung mass natural frequency.

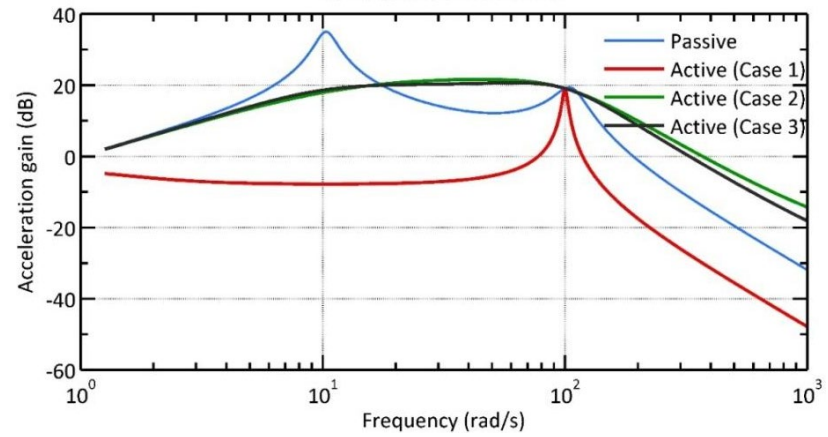

(a)

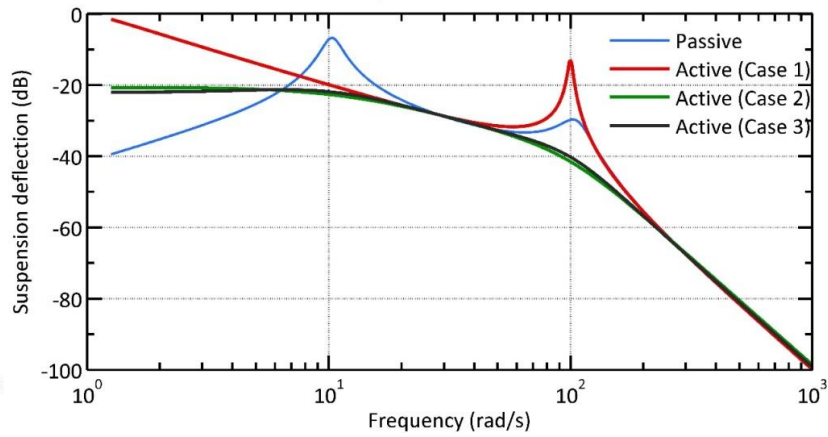

(b) 


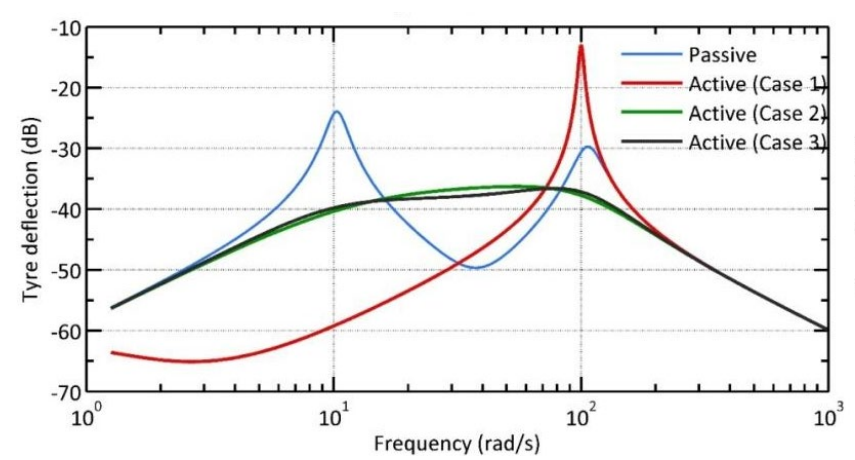

(c)

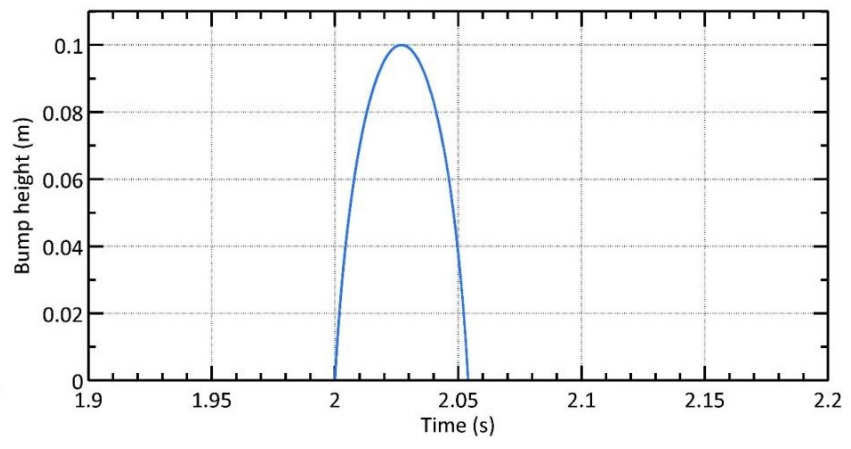

(d)

Figure 2. Front and rear 2 DOF (bump) for (a) sprung mass acceleration, (b) suspension deflections, (c) tyre deflections and, (d) road profile (bump).

Figure 2(b) shows the frequency response of the suspension deflection transfer function comparison. Case 1 is with heavily weighted sprung mass acceleration. Gain at sprung mass natural frequency is about $-20 \mathrm{~dB}$. Due to the presence of gain term g3, the Suspension deflection worsens at the unsprung mass natural frequency. Case 2 shows the frequency response for the suspension deflection transfer function for the system, which has moderately weighted suspension deflection. The gain has a smaller value at a sprung mass natural frequency (about $-30 \mathrm{~dB}$ ). A very good improvement of the suspension deflection is obtained; about $-40 \mathrm{~dB}$ to that of $-12 \mathrm{~dB}$ as in case 1 . Case 3 shows the suspension deflection transfer function for heavily weighted suspension and tyre deflection.

The frequency response of the tyre deflection transfer function with weighted sprung mass acceleration is shown in Figure 2(c). At sprung mass natural frequency, tyre deflection improves, while at the unsprung mass natural frequency, it deteriorates. The gain is around $-60 \mathrm{~dB}$ at the sprung mass natural frequency, compared to $-25 \mathrm{~dB}$ for the passive system. With an active system, the gain in the unsprung mass mode is $-8 \mathrm{~dB}$, but with a passive system, it is $-30 \mathrm{~dB}$. With moderately weighted suspension and tyre deflection, Case 2 demonstrates the frequency response for the tyre deflection transfer function. At the second natural frequency, the gain is about $-42 \mathrm{~dB}$ as compared to $-8 \mathrm{~dB}$ in case 2 . Case 3 shows the tyre deflection transfer function for the heavily weighted suspension and tyre deflection. The response near the natural frequencies is the same. But there is a small decrease in the response between two natural frequencies; hence it appears flat.

\section{Time-Domain Analysis}

This analysis is done to find the transient response of the system to the inputs in the time domain. Thus, the actual road inputs can be simulated, and the response can be studied. Two types of road inputs are studied; bump input and random road input. The bump profile is shown in Figure 2(d) as modelled earlier. The bump is assumed to have $0.1 \mathrm{~m}$ height and $0.3 \mathrm{~m}$ length. Figure 3(a) shows the transient response of the system to the given bump input. The passive system goes on oscillating till about $7 \mathrm{~s}$, whereas the active system does not oscillate at all. It reaches a maximum of 0.035 $\mathrm{m}$ and dies off quickly.

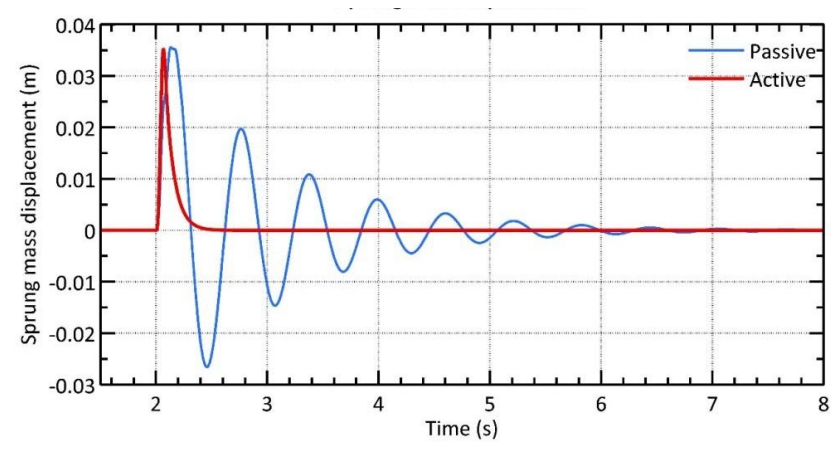

(a)

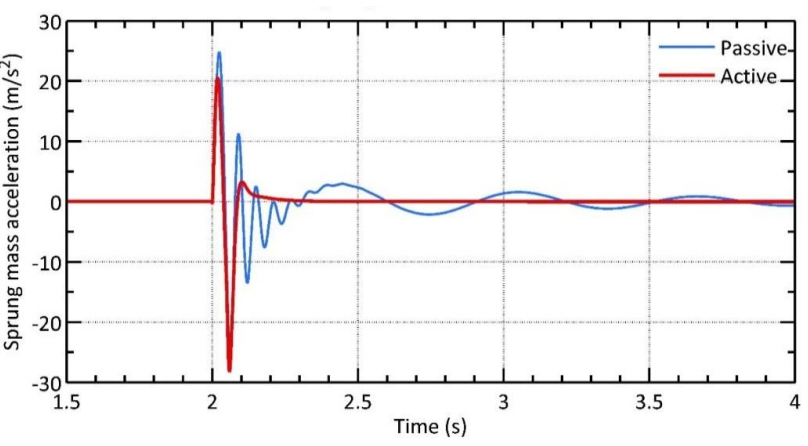

(b) 


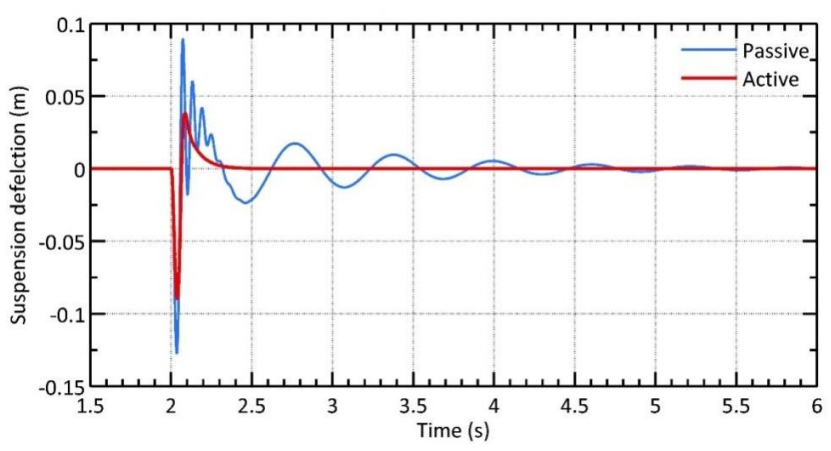

(c)

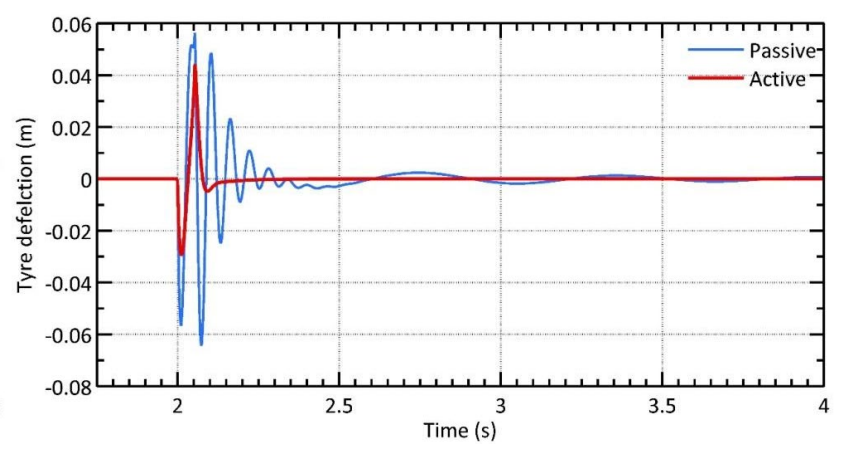

(d)

Figure 3. Front and rear 2 DOF (bump) for (a) active sprung mass displacement, (b) sprung mass acceleration, (c) suspension deflections, and (d) tyre deflections.

Figure 3(b) depicts the sprung mass acceleration's transient response. Its maximum speed is around $20 \mathrm{~m} / \mathrm{s}^{2}$, which is lower than the passive system's maximum speed. Without oscillation, the sprung mass acceleration soon decays to zero. Thus, the active suspension has improved ride comfort to a considerable extent. Figure 3(c) shows the transient response for the suspension deflection when the bump is encountered. The suspension deflection is heavily improved. The peak value is $0.04 \mathrm{~m}$, which is slightly less than half of the value attained in the case of the passive suspension. Passive system response becomes steady only after 5.5, whereas the active system response attains a steady state at about $2.5 \mathrm{~s}$. Figure 3(d) shows the transient response for the tyre deflection. Active system considerably improves the transient tyre deflection. The peak value of tyre deflection for an active system is $0.045 \mathrm{~m}$, which is slightly less than the value for the passive system. The oscillation dies off much quicker for an active system, i.e. at about $2.1 \mathrm{~s}$ as compared to $3.5 \mathrm{~s}$ in a passive system.

Transient response analysis over a bump gives only a partial idea about the suspension performance. More practical situations can be simulated by providing a random road as input to the model. The random road modelling procedure was outlined previously and the simulation time is 20 seconds. Figure 4(a) shows the random road profile. Figure 4(b) shows the transient response of the sprung mass displacement of the active system; it is clear that better road shock isolation is obtained through the implementation of the active system. Figure 4(c) shows the transient response of the sprung mass acceleration. The values of acceleration for an active system are somewhat lower than those for a passive system. It will be difficult to conclude from the figure as it is full of oscillations. Hence root mean square values of all the parameters are tabulated at the end for comparison. Figure 4(d) shows the transient response of the suspension deflection for active and passive suspension systems. It is clear from the plot that the active suspension improves suspension deflection.

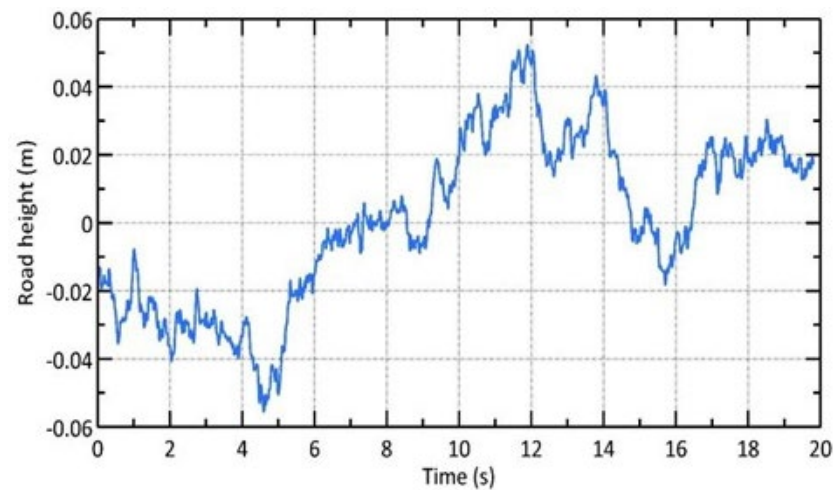

(a)

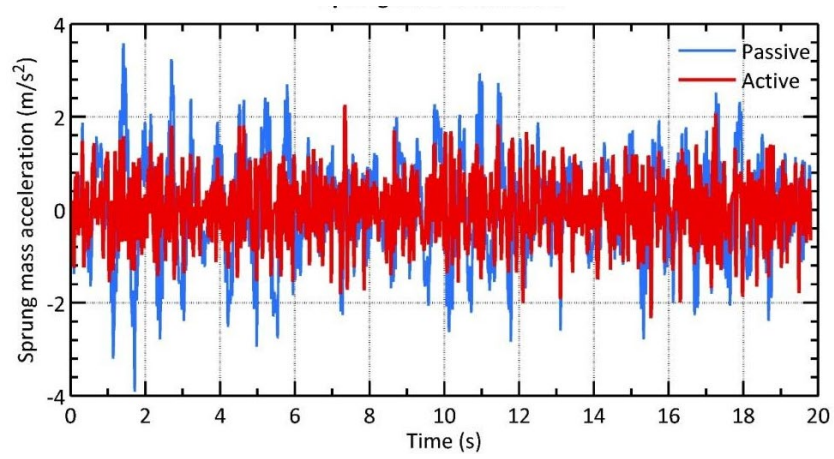

(c)

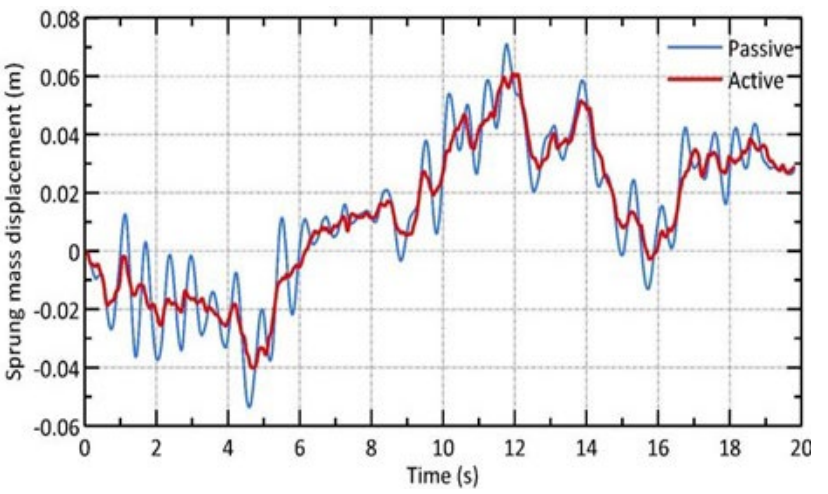

(b)

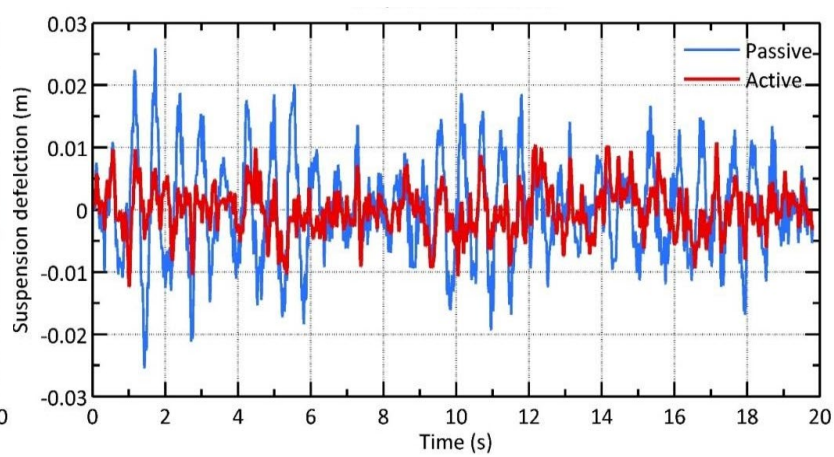

(d) 


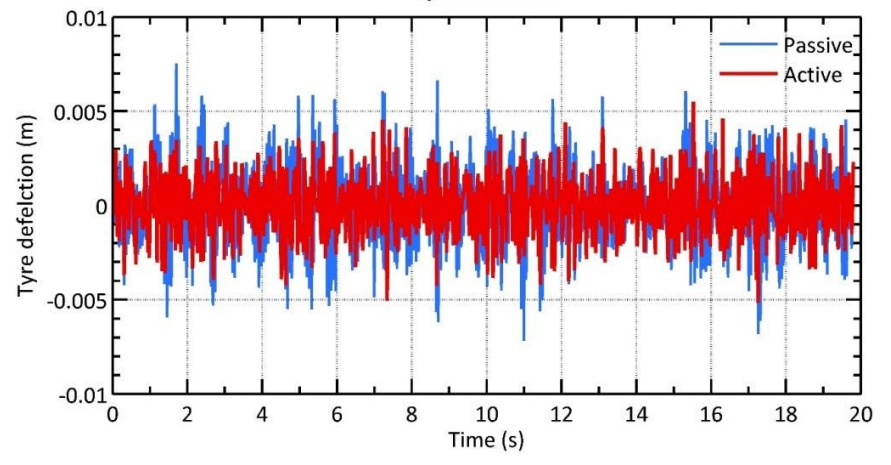

(e)

Figure 4. (a) Road profile, (b) sprung mass displacement, (c) sprung mass acceleration, (d) suspension deflections, and (e) tyre deflections.

The actuators exert force on the sprung and unsprung mass of the system so that their movements are restricted and thereby reducing the suspension space requirement. Figure 4(e) shows the transient response of the tyre deflection for active and passive suspension systems. Tyre deflection is responsible for dynamics tyre load variation, which relates to road-holding performance. It is difficult to draw solid conclusions from the plot, so the Root Mean Square (RMS) value comparisons are provided. From Table 1, it is clear that the RMS value of the active systems is better than the passive system. Hence it can be said that ride comfort and road holding performance improved by implementing the active suspension system.

Table 1. Root mean square value comparison.

\begin{tabular}{lcccc}
\hline & $\begin{array}{c}\text { Displacement on sprung } \\
\text { mass }\end{array}$ & $\begin{array}{c}\text { Acceleration on sprung } \\
\text { mass }\end{array}$ & $\begin{array}{c}\text { Deflection on } \\
\text { suspension }\end{array}$ & $\begin{array}{c}\text { Deflection on } \\
\text { tyre }\end{array}$ \\
\hline Passive & 0.0290 & 1.0556 & 0.0077 & 0.0019 \\
Active & 0.0275 & 1.0275 & 0.0037 & 0.0014 \\
\hline
\end{tabular}

\section{DOF Planar Model for Active Suspension System}

The planar model for the active suspension system is considered for the numerical analysis to evaluate the deflection in active components of suspension. The mass which considered for the respective system and the parameter values are given in Table 2.

Table 2. Parameter values used for the simulation.

\begin{tabular}{cc}
\hline Parameter & Value \\
$m_{s}$ & $200 \mathrm{~kg}$ \\
$m_{u f}$ & $15 \mathrm{~kg}$ \\
$m_{u r}$ & $18 \mathrm{~kg}$ \\
$\mathrm{I}$ & $38 \mathrm{kgm}^{2}$ \\
$w b$ & $1.4 \mathrm{~m}$ \\
$c f$ & $0.7 \mathrm{~m}$ \\
$c r$ & $0.7 \mathrm{~m}$ \\
$K_{s f}$ & $15,000 \mathrm{~N} / \mathrm{m}$ \\
$K_{s r}$ & $24,000 \mathrm{~N} / \mathrm{m}$ \\
$C_{s f}$ & $500 \mathrm{Ns} / \mathrm{m}$ \\
$C_{s r}$ & $750 \mathrm{Nm} / \mathrm{s}$ \\
$K_{t f}, K_{t r}$ & $1,80,000 \mathrm{~N} / \mathrm{m}$ \\
\hline
\end{tabular}

\section{Frequency domain analysis}

The performance improves, and there is not much improvement after the pitch natural frequency of $13 \mathrm{rad} / \mathrm{s}$. The oscillations in the passive system are due to the correlated input given to the system, which means that the rear wheel is given the same input as the front wheel but with a delay. With a wheelbase of $1.4 \mathrm{~m}$ and at a velocity of $40 \mathrm{~km} / \mathrm{h}$, the delay for the rear wheel input is taken as $0.12 \mathrm{~s}$. Figure 5(b) shows the frequency response for the pitch response of the system. There is a considerable improvement in the response of the active system throughout the frequency range. A small peak in the response of the active system is found near the unsprung mass natural frequency but is still below that of the passive system. Figure 5(c) shows the frequency response for the sprung mass acceleration for the active and passive suspension system. A clear improvement in the response is found till $13 \mathrm{rad} / \mathrm{s}$. After that, there is no significant improvement in the active system. However, the effect of correlated input is lower in an active system. At the unsprung mass natural frequency, the acceleration gain is slightly larger than the passive system gain. Figure 5(d) shows the 
frequency response for the sprung mass pitch acceleration for the active and passive suspension system. The pitch acceleration transfer functions have improved significantly in the active system. Nowhere in the frequency range has the gain crossed the gain of the passive system.

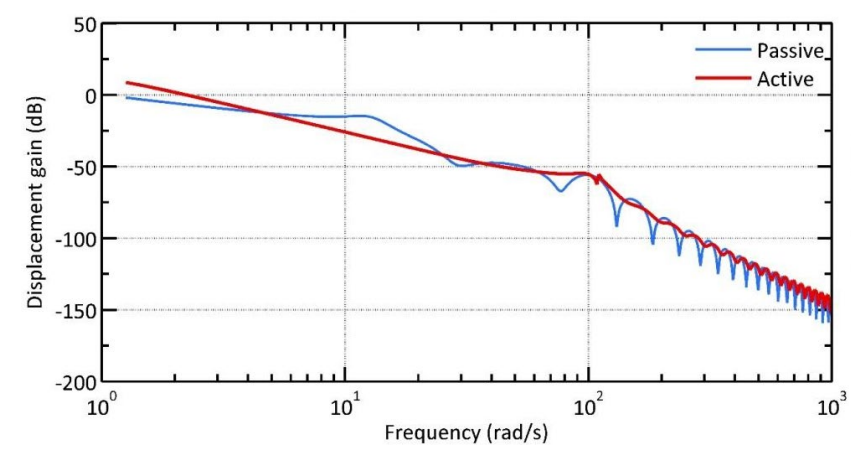

(a)

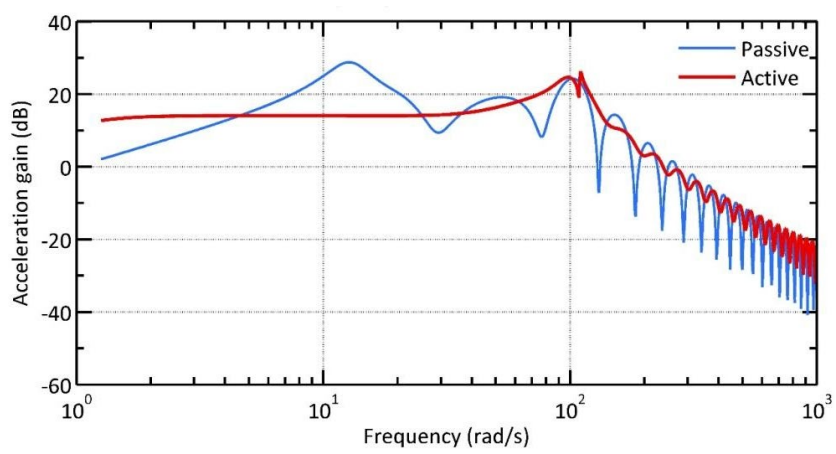

(c)

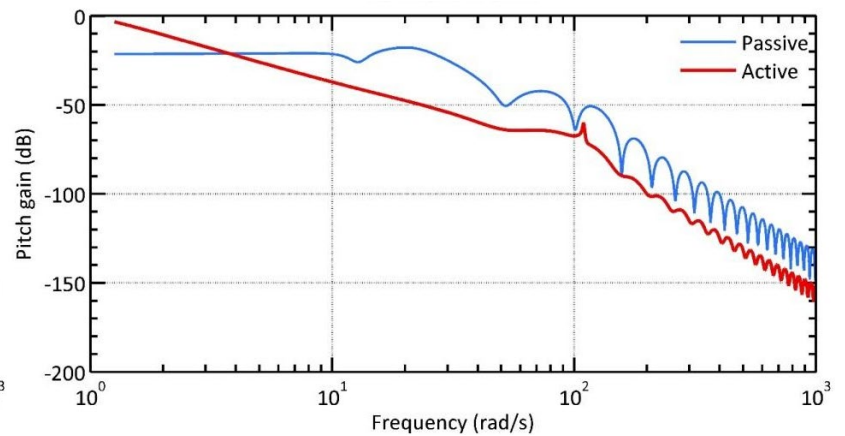

(b)

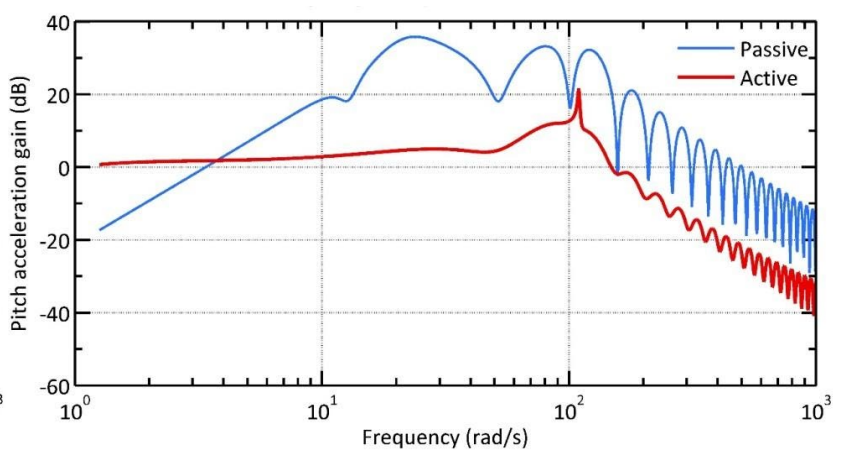

(d)

Figure 5. Front and rear, 4 DOF for (a) sprung mass displacement, (b) sprung mass pitch, (c) sprung mass acceleration, and (d) sprung mass pitch acceleration.

Figure 6(a) shows the frequency response for the front suspension deflection. In an active suspension system, the suspension deflection is minimum as compared to the passive system. There is a dip in the response of the passive system near $12 \mathrm{rad} / \mathrm{s}$. Figure 6(b) shows the frequency response of the rear suspension deflection. There are no significant variations in the transfer function in both cases after the first natural frequency. Figure 6(c) shows the frequency response of the front tyre deflection transfer function. There is a good improvement in the active system response in the region of first and third natural frequencies. There is a small drop in performance near $31 \mathrm{rad} / \mathrm{s}$. But at unsprung mass natural frequencies, the performance is much better than passive suspension systems. Figure $6(\mathrm{~d})$ shows the frequency response of the rear tyre deflection transfer function. From the plot, it is clear that there is no considerable performance improvement in the rear tyre deflection functions, even though there is a slight improvement near the frequency range from $25 \mathrm{rad} / \mathrm{s}$ to $100 \mathrm{rad} / \mathrm{s}$.

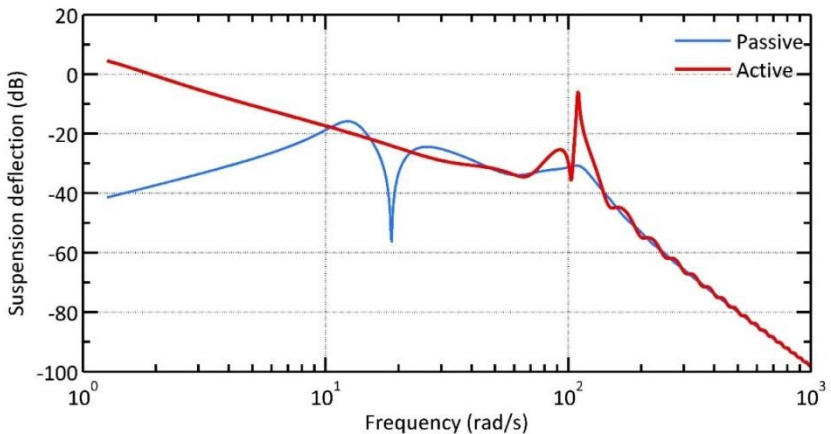

(a)

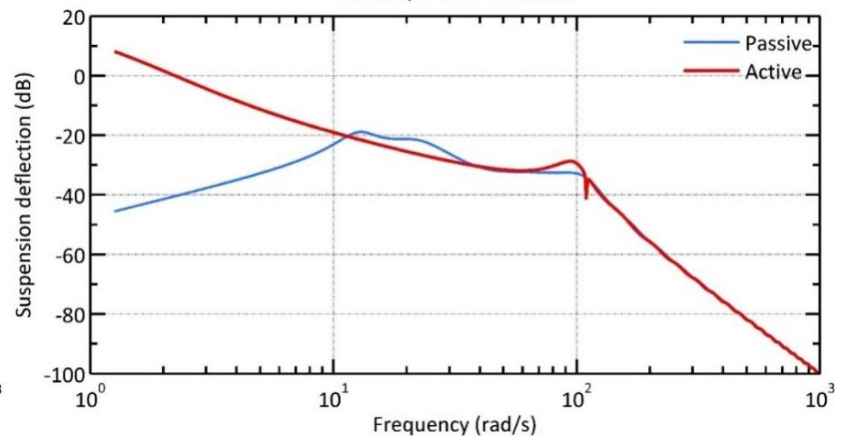

(b) 


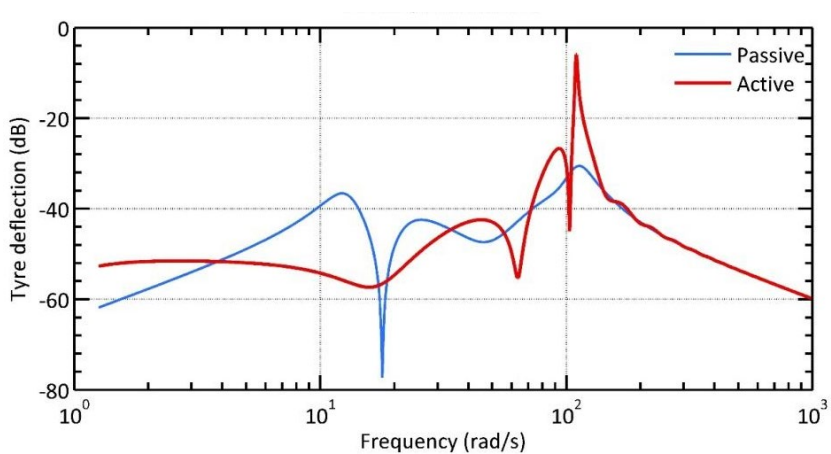

(c)

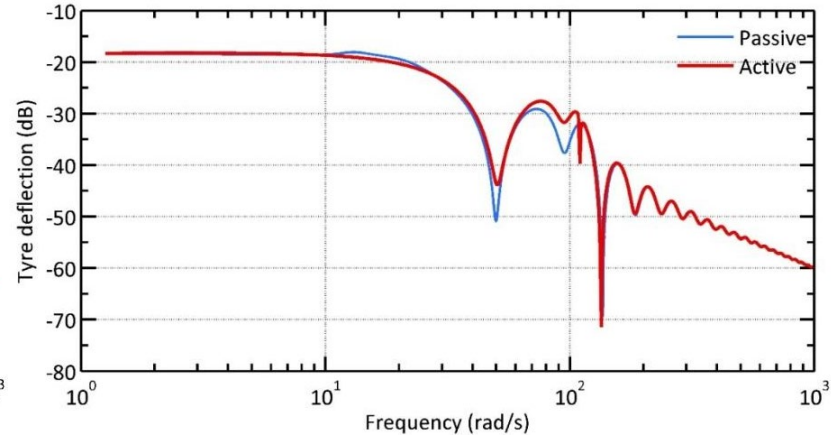

(d)

Figure 6. The 4 DOF for (a) front suspension deflection, (b) rear suspension deflection, (c) front tyre deflection, and (d) rear tyre deflection

From all the above plots of frequency response, it is clear that the ride quality, handling, and road-holding performances have been improved in the active suspension system. All the transfer functions except rear suspension deflection and rear tyre deflection have been improved while those two seem to remain the same and not worsened.

\section{Time-domain analysis}

Road input given is the same as that given for the 2 DOF model. Vehicle speed is assumed to be $40 \mathrm{~km} / \mathrm{h}$ and the delay was calculated as $0.126 \mathrm{~s}$. The same input is applied to the rear wheel with a delay of $0.126 \mathrm{~s}$. Figure 7(a) shows the transient response of the sprung mass displacement for the active and passive systems. The input starts at $2 \mathrm{~s}$. The response of the active system has a very good improvement from the passive system response. The response after hitting the first bump is effectively absorbed by the controller. The second peak occurs while the rear wheel encounters the bump. The displacement reduces gradually, which is assisted by the control forces. Figure 7(b) shows the transient sprung mass pitch response of the system while it encounters a bump. The passive system first pitches in the anti-clockwise direction (negative sign) and then pitches in the clockwise direction (positive pitch). The active system pitches to a very small value due to the presence of the control forces. Figure 7(c) shows the sprung mass acceleration response of the active and passive systems. The plot shows some similarities to that of the sprung mass displacement response. While the front tyre encounters the bump, its effect is nullified by the control system. When the rear wheel encounters the bump, a peak in sprung mass displacement is identified, which gets reflected in the acceleration plot. Figure 7(d) shows the transient response of the sprung mass pitch acceleration. The active systems improve the sprung mass pitch acceleration response. The peak value of the active system is only one-fifth of the peak value in the passive system.

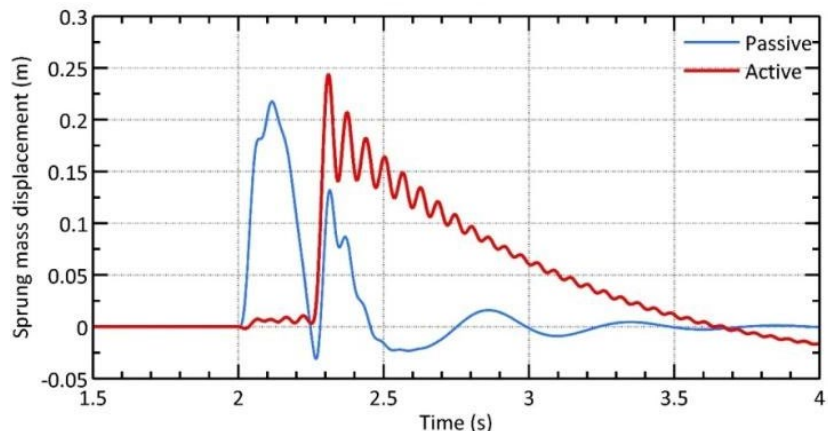

(a)

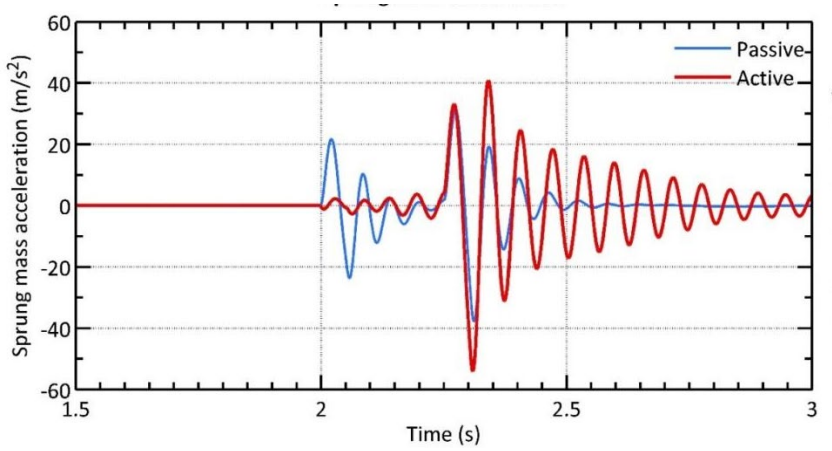

(c)

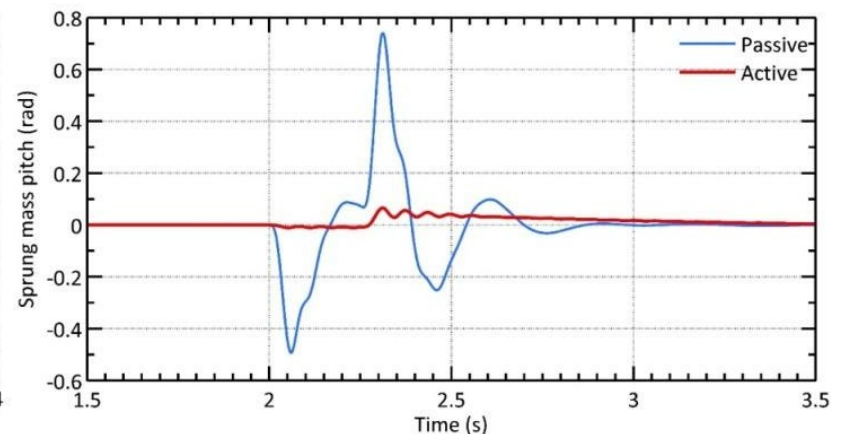

(b)

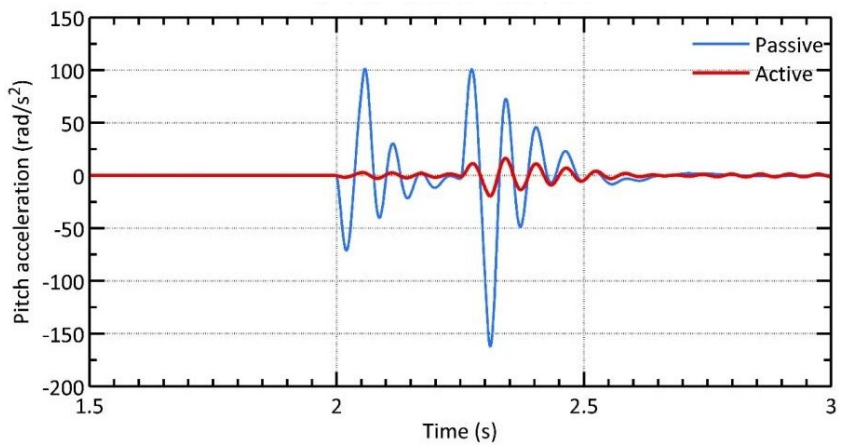

(d)

Figure 7. Bump 4 DOF for (a) sprung mass displacement, (b) sprung mass pitch, (c)sprung mass acceleration, and (d) sprung mass pitch acceleration 
Figure 8(a) shows the transient response of front suspension deflection. There is a small improvement in the front suspension deflection. This may be because while finding the LQR control gain sprung mass acceleration was more penalised and suspension deflection was comparatively less penalised. This practically means that while formulating the problem, suspension deflection will have less weightage in the cost function than sprung mass bounce and pitch acceleration. Figure 8(b) shows the transient response of the rear suspension deflection; the oscillatory behaviour of the system has been controlled by the actuators. The maximum suspension deflection is also decreased by the actuators. Figure 8(c) shows the transient response of the front tyre deflection.

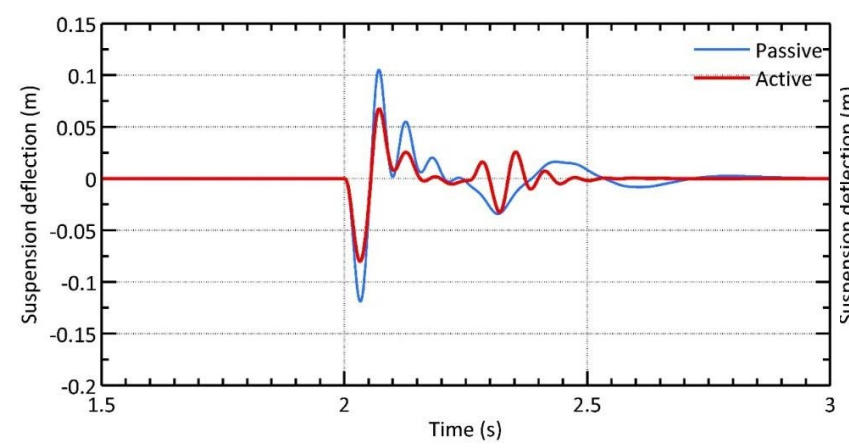

(a)

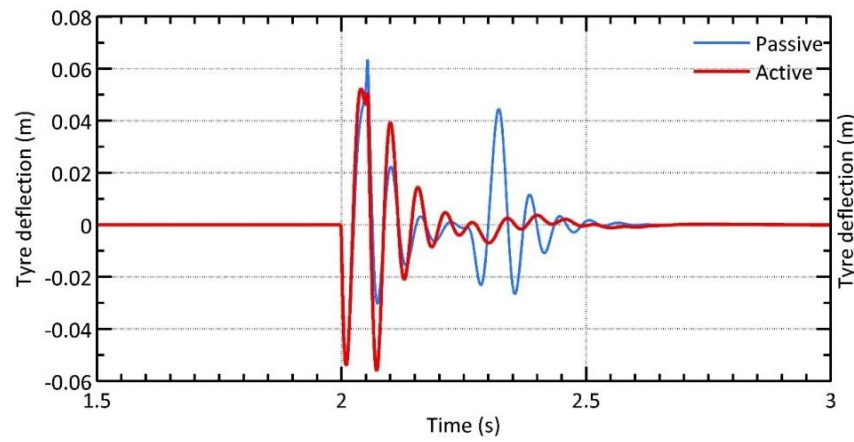

(c)

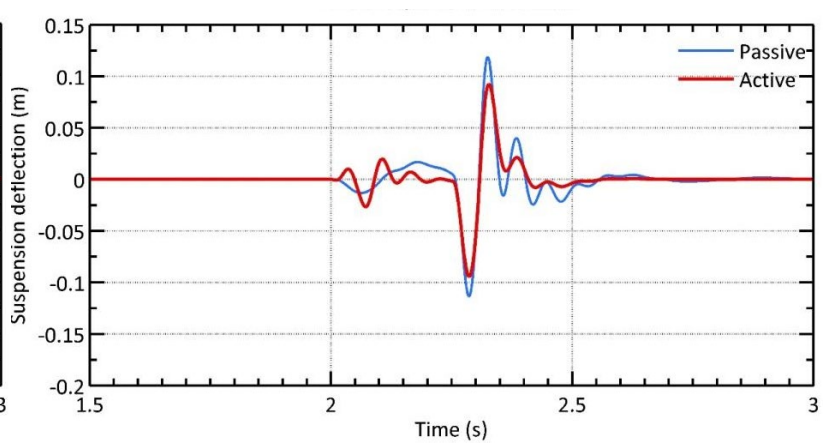

(b)

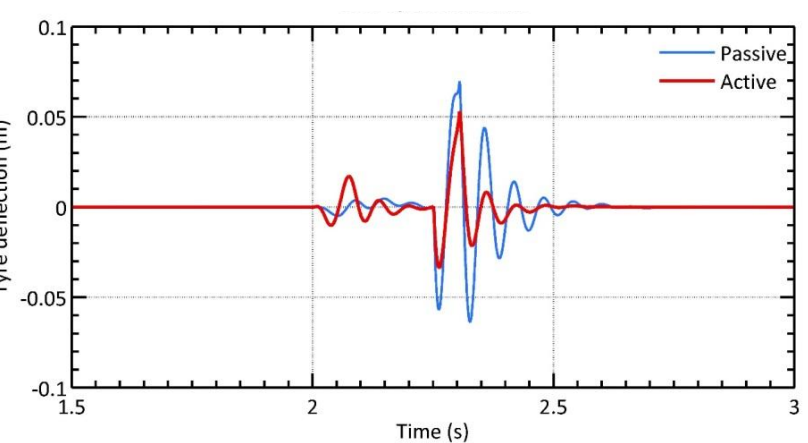

(d)

Figure 8. Bump 4 DOF active for (a) front suspension deflection, (b) rear suspension deflection, (c) front tyre deflection, and (d) rear tyre deflection.

The performance is observed to be improved in the active system, where the peak tyre deflection is reduced in the active suspension system. The oscillations die out faster in the active system, which indicates a decreased dynamic tyre load variation and increased road-holding performance. Figure 8(d) shows the transient response of the rear tyre deflection. The response of the active system is worsened initially. But after the rear wheel encounters the bump, the movement of the rear unsprung mass is controlled by the rear actuator, which reduces the oscillation and thereby reduces the dynamic tyre load variation. The peak values are also minimised by the control actuators. The random road used here for simulation is the same used in the simulation for the 2 DOF model. The same input is given to the rear wheel with a delay of $0.126 \mathrm{~s}$.

Figure 9(a) depicts the sprung masses displacement's transient reaction to the random road input. The active system's sprung mass displacement decreases dramatically, as seen in the graph. After the outcomes of the sample active suspension system, the RMS value comparison is presented at the conclusion of this chapter. Figure 9(b) shows the pitch response of both systems. The pitch response of the active system has good improvement than that of the passive system. Even though the sprung mass pitches excessively, the pitch acceleration will be minimum, which is the required criterion. This is because the weighting factor for the sprung mass acceleration and pitch acceleration has been given unity while all other states are less penalised. Figure 9(c) shows the transient reaction of the sprung mass acceleration.

The active system shows a considerable improvement than the passive counterpart. Sprung mass acceleration and pitch acceleration are the most penalised states in the cost function. So the control gains are formulated, which minimised sprung mass acceleration and pitch acceleration. The transient reaction of the sprung masses pitch acceleration is seen in Figure 9(d). It has been effectively minimised. This enhanced both the comfort and handling of the vehicle. Figure 10(a) and Figure 10(b) shows the transient response of the front and rear suspension deflections. The active suspension system demonstrates minimised front and rear suspension deflections. As the plot is very oscillating, it is not possible to conclude the plot directly. Hence RMS analysis is done. Figure 10(c) and Figure10(d) show the transient response for the front and rear tyre deflections. Active systems have been found to have reduced tyre deflections than passive ones. These reduced tyre deflections will signify a reduced dynamic tyre load variation and ensure a better road holding capability. Front tyre deflection is less than the rear tyre deflection. 


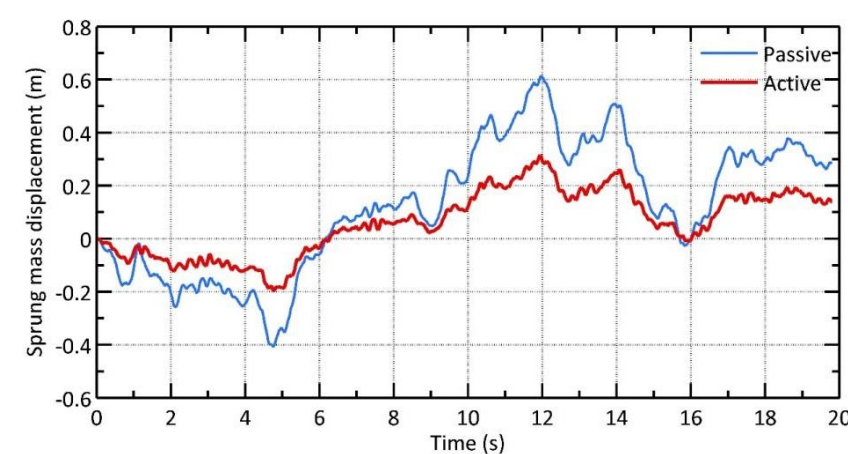

(a)

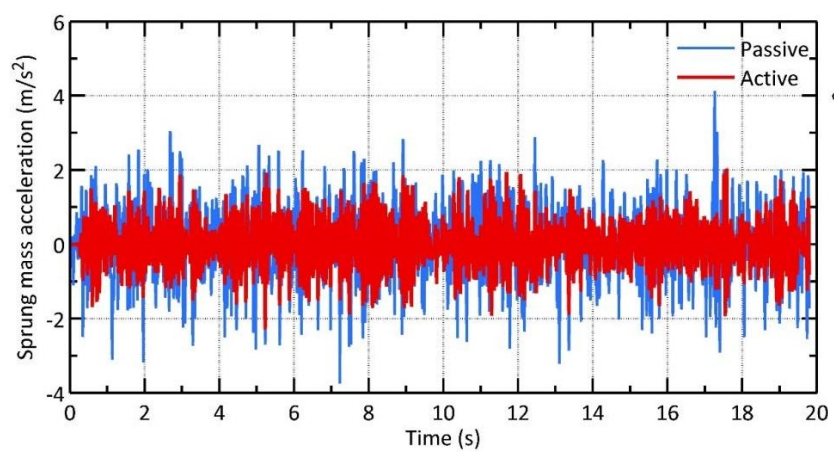

(c)

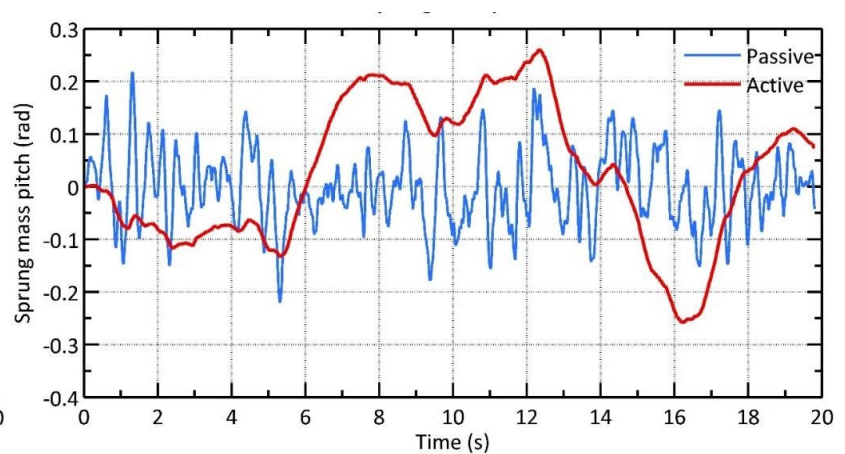

(b)

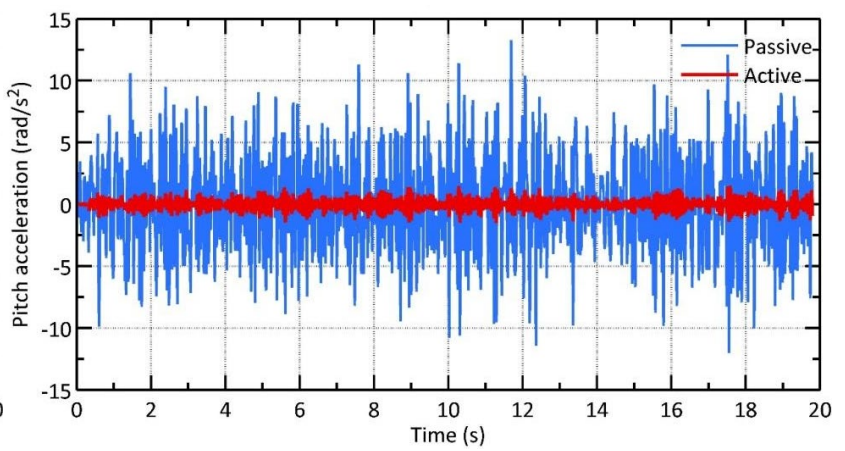

(d)

Figure 9. Random 4 DOF (active) for (a) sprung mass displacement, (b) sprung mass pitch, (c) sprung mass acceleration, and (d) sprung mass pitch acceleration.

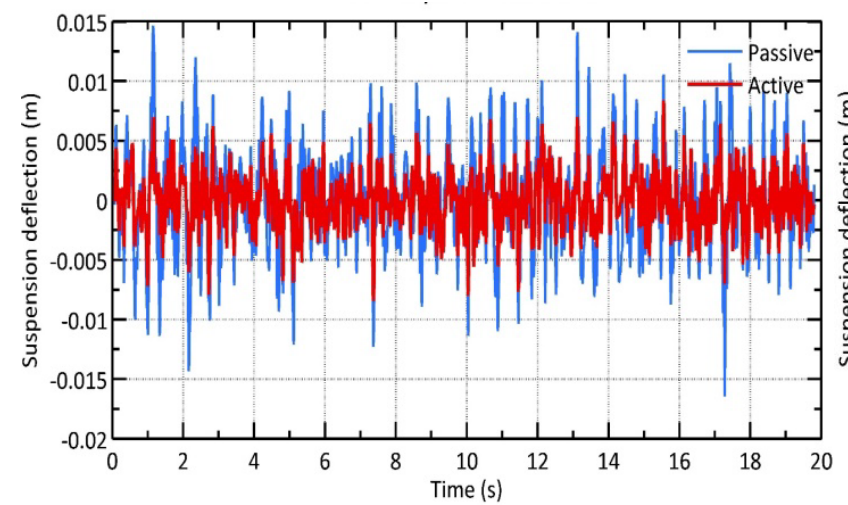

(a)

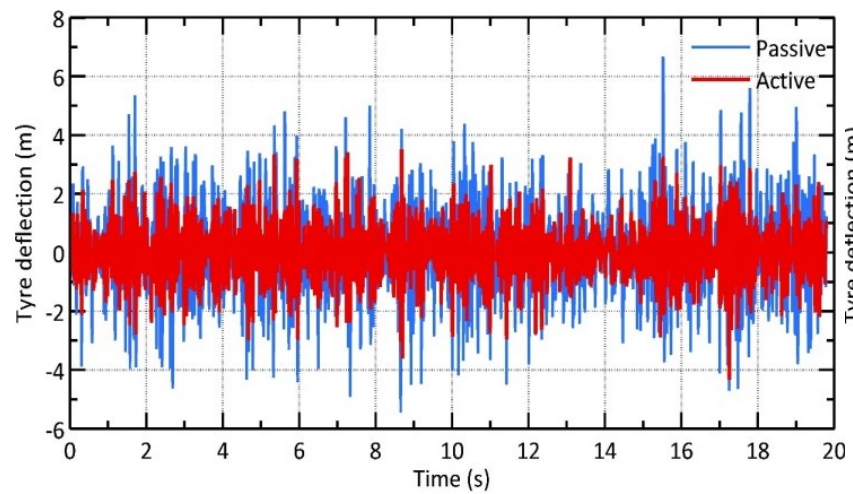

(c)

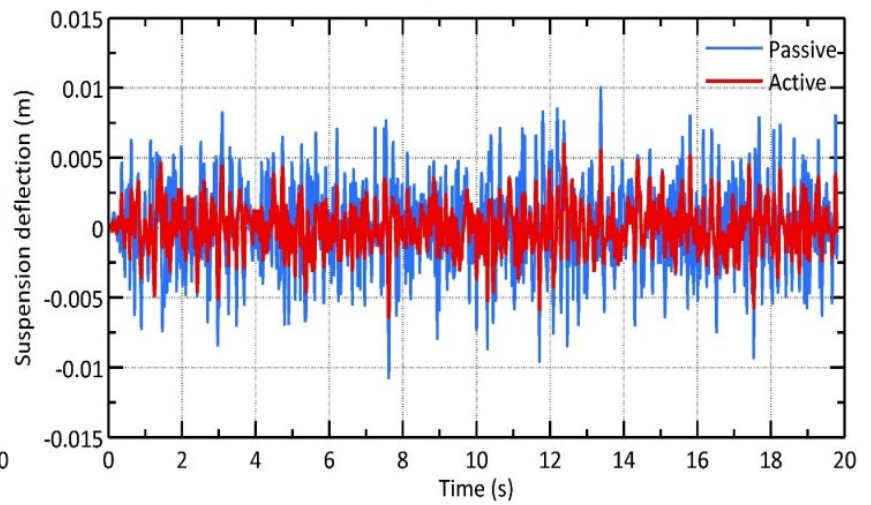

(b)

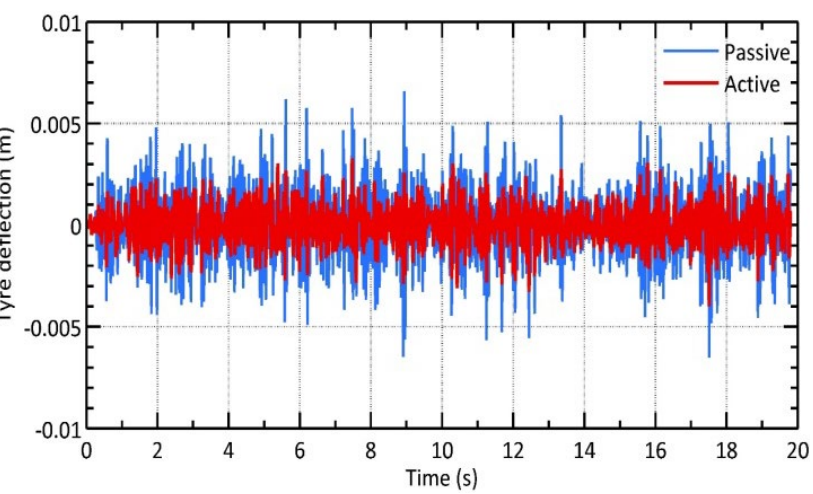

(d)

Figure 10. Random, 4 DOF, active, (a) Front suspension deflection, (b) Rear suspension deflection, (c) Front tyre deflection, (d) Rear tyre deflection

All the performance parameters for the 4 DOF planar model have been plotted. Since solid conclusions can't be drawn from plots due to the highly oscillating nature, RMS values are computed and tabulated after the next section. Table 4 shows the comparison for the root mean square value of the necessary parameters computed for passive and active 
suspension systems and data validation with respect to sprung mass displacement and acceleration-the deflection of front and rear suspension systems and tyres for four degrees of freedom.

Table 4. Parameters of the 4 DOF system.

\begin{tabular}{lcccc}
\hline \multirow{2}{*}{ Parameters } & \multicolumn{2}{c}{ Passive suspension } & \multicolumn{2}{c}{ Active suspension } \\
\cline { 2 - 5 } & Bump Input & Random road input & Bump Input & Random road input \\
\hline Sprung mass displacement & 0.0104 & 0.0261 & 0.0049 & 0.0251 \\
Sprung mass pitch & 0.0083 & 0.0086 & 0.0033 & 0.0068 \\
Sprung mass acceleration & 0.4487 & 0.3672 & 0.2403 & 0.1864 \\
Sprung mass pitch acceleration & 0.3685 & 0.3290 & 0.2098 & 0.1763 \\
Front suspension deflection & 0.0120 & 0.0102 & 0.0075 & 0.0074 \\
Rear suspension deflection & 0.0131 & 0.0125 & 0.0117 & 0.0101 \\
Front tyre deflection & 0.0081 & 0.0277 & 0.0034 & 0.0276 \\
Rear tyre deflection & 0.0061 & 0.0269 & 0.0064 & 0.0268 \\
\hline
\end{tabular}

\section{CONCLUSION}

In the case of the 2 DOF planar model, all the needed performance parameters, namely sprung mass acceleration, suspension deflection, and tyre deflection improved when the active suspension was implemented. In the case of the 4 DOF model, simulation with active suspension has been done. Implementation of the active suspension has visible performance improvements than the passive system. RMS value of sprung mass bounce acceleration has decreased from $0.3672 \mathrm{~m} / \mathrm{s}^{2}$ to $0.1864 \mathrm{~m} / \mathrm{s}^{2}$, the amount of deflection in the front suspension reduces from $0.0102 \mathrm{~m}$ to $0.0074 \mathrm{~m}$, and the amount of deflection in the rear suspension reduces from 0.0125 to $0.0101 \mathrm{~m}$. The front tyre deflection decreased from 0.0277 to $0.0276 \mathrm{~m}$, and the amount of deflection in the rear suspension reduced from $0.0269 \mathrm{~m}$ to $0.0268 \mathrm{~m}$.

\section{ACKNOWLEDGEMENT}

The authors would like to thank Vel Tech Rangarajan Dr. Sagunthala R\&D Institute of Science and Technology for supporting and completing this research on the active suspension system.

\section{REFERENCES}

[1] M.A.A. Abdelkareem et al., "Monte Carlo sensitivity analysis of vehicle suspension energy harvesting in frequency domain," J. Adv. Res., vol. 24, pp. 53-67, 2020, doi: 10.1016/j.jare.2020.02.012.

[2] R. Zhang et al., "A comprehensive comparison of the vehicle vibration energy harvesting abilities of the regenerative shock absorbers predicted by the quarter, half and full vehicle suspension system models," Appl. Energy, vol. 272, pp. 115180, 2020 , doi: $10.1016 / j$.apenergy.2020.115180 .

[3] L. Tu et al., "A novel negative stiffness magnetic spring design for vehicle seat suspension system,” Mechatron., vol. 68, pp. 102370, 2020, doi: 10.1016/j.mechatronics.2020.102370 .

[4] D-S. Yoon, G-W. Kim, and S-B. Choi, "Response time of magnetorheological dampers to current inputs in a semi-active suspension system: Modeling, control and sensitivity analysis," Mech. Syst. Signal Process., vol. 146, pp. 106999, 2021, doi: 10.1016/j.ymssp.2020.106999.

[5] M. Abid, J. Yu, Y. Xie, and A. Salam, "Conceptual design, modelling and compliance characterisation of a novel 2-DOF rotational pointing mechanism for fast steering mirror," Chinese J. Aeronaut., vol. 33, pp. 3564-3574, 2020, doi: 10.1016/j.cja.2020.03.032.

[6] J. Fan et al., "On discontinuous dynamics of a 2-DOF oscillator with an one-sided rigid obstacle," Int J. Non Linear Mech., vol. 118, pp. 103261, 2019, doi: 10.1016/j.ijnonlinmec.2019.103261.

[7] K. Radhakrishnan et al., "Torsional vibration analysis of torsion bar spring for off road vehicle driver seat," Mater. Today: Proc., vol. 21, pp. 1-4, 2019, doi: 10.1016/j.matpr.2019.06.736.

[8] P. Gandhi, S. Adarsh, and KI. Ramachandran, "Performance Analysis of Half Car Suspension Model with 4 DOF using PID, LQR, FUZZY and ANFIS Controllers," Procedia Comput. Sci., vol. 115, pp. 2-13, 2017, doi: 10.1016/j.procs.2017.09.070.

[9] AG Mohite, and A.C. Mitra, "Development of linear and non-linear vehicle suspension model," Mater. Today: Proc., vol. 5, no. 2, pp. 4317-4326, 2018, doi: 10.1016/j.matpr.2017.11.697.

[10] P. Neri, F. Bucchi, and D. Passarelli, "A multilevel finite element-multibody approach to design the suspension system for the road transportation of SSR1 cryomodule," Transportation Engineering, vol. 2, pp. 100017, 2020, doi: 10.1016/j.treng.2020.100017

[11] S.-H. Lee, et al., "Fatigue life analysis of wheels on guideway vehicle using multibody dynamics," Int. J. Precis. Eng., vol. 10, no. 5, pp. 79-84, 2009, doi: 10.1007/s12541-009-0097-x.

[12] H. Aleksander, "Optimal linear preview control of active vehicle suspension, vehicle system dynamics," International Journal of Vehicle Mechanics and Mobility, vol. 21, no. 1, pp. 167-195, 1992, doi: 10.1080/00423119208969008

[13] D.A. Crolla, and M.B.A. Abdel-Hady, "Active suspension control; performance comparisons using control laws applied to a full vehicle model, vehicle system dynamics," International Journal of Vehicle Mechanics and Mobility, vol. 20, no. 2, pp. 107-120, 1991, doi: 10.1080/00423119108968982.

[14] F. Fruhauf, R. Kasper, and J. Lückel, "Design of an active suspension for a passenger vehicle model using input processes with time delays, vehicle system dynamics," International Journal of Vehicle Mechanics and Mobility, vol. 14, no. 1-3, pp. 115120, 1985, doi: 10.1080/00423118508968811 
[15] N. Louam, D.A. Wilson, and RS Sharp, "Optimisation and performance enhancement of active suspensions for automobiles under preview of the road, vehicle system dynamics," International Journal of Vehicle Mechanics and Mobility, vol. 21no. 1, pp. 39-63, 1992, doi: 10.1080/00423119208969001.

[16] B.A. Albassam, A.A. Fayed, and M.M. Elmadany, "Optimal linear preview control of slow active suspension systems," In Proceedings of the 7th Saudi Engineering Conference, 2007, pp. 1-12

[17] A.G. Thompson and C.E.M. Pearce, "Performance index for a preview active suspension applied to a quarter-car model, vehicle system dynamics," International Journal of Vehicle Mechanics and Mobility, vol. 35, no. 1, pp. 55-66, 2001, doi: 10.1076/vesd.35.1.55.5616.

[18] R. Zhang, and X. Wang, "Parameter study and optimisation of a half-vehicle suspension system model integrated with an armteeth regenerative shock absorber using Taguchi method," Mech. Syst. Signal Process., vol. 126, pp. 65-81, 2019, doi: 10.1016/j.ymssp.2019.02.020.

[19] E. Risaliti et al., "Multibody model based estimation of multiple loads and strain field on a vehicle suspension system. Mech. Syst. Signal Process., vol. 123, pp. 1-25, 2019, doi: 10.1016/j.ymssp.2018.12.024 .

[20] M. M. Fateh, and Seyed S. Alavi, "Impedance control of an active suspension system," J. Mechatron, vol. 19, no. 1, p. 134140, 2009, doi: 10.1016/j.mechatronics.2008.05.005.

[21] H. Chen, Z. -Y. Liu, and P.-Y. Sun , "Application of constrained H_Control to active suspension systems on half-car models", J. Dyn Syst Meas Control, vol. 127, no. 3, pp. 345-354, 2005, doi: 10.1115/1.1985442. 